\title{
The ISC Bulletin as a comprehensive source of earthquake source mechanisms
}

\author{
Konstantinos Lentas, Domenico Di Giacomo, James Harris, and Dmitry A. Storchak \\ International Seismological Centre, Pipers Lane, Thatcham, Berkshire, RG194NS, UK \\ Correspondence: Konstantinos Lentas (kostas@isc.ac.uk)
}

Received: 21 November 2018 - Discussion started: 26 November 2018

Revised: 3 April 2019 - Accepted: 23 April 2019 - Published: 29 April 2019

\begin{abstract}
In this article we summarize the availability of earthquake source mechanisms in the Bulletin of the International Seismological Centre (ISC). The bulletin in its current status contains $\sim 81000$ seismic events with only one associated mechanism solution and $\sim 25000$ events with at least two associated source mechanisms. The main sources of earthquake mechanisms in the ISC Bulletin are reported solutions provided by data contributors and ISC-computed focal mechanisms based on first motion polarities. Given the importance of using pre-determined fault plane solutions in different types of studies, here we briefly discuss the methodologies adopted by major data providers to the ISC and investigate the intra-event variability of the source mechanisms. We conclude that the overall agreement among different earthquake mechanisms for the same event as reported by different sources can show a similarity coefficient as high as $80 \%$, based on the rotation angles of their bestfitting double couple solutions, for the majority of the cases. The earthquake source mechanisms discussed in this work are freely available within the ISC Bulletin websearch at http://doi.org/10.31905/D808B830.
\end{abstract}

\section{Introduction}

The International Seismological Centre (ISC, http://www. isc.ac.uk/, last access: April 2019) currently collects station readings, hypocentre solutions, and other earthquake bulletin data from approximately 150 agencies around the world. The ISC Bulletin contains over 7.6 million seismic events (mostly earthquakes, as well as chemical and nuclear explosions, mine blasts, and mining-induced events, and other types of seismic events), and approximately 256 million associated seismic station readings of arrival times, amplitudes, periods, and first motion polarities (International Seismological Centre, 2018, database last accessed in March 2019).

Considerable effort is put into making sure that the station readings reported by different agencies belong to the correct seismic event. In the first instance, all parametric data sent to the ISC is collected and grouped automatically into unique seismic events. As soon as an event is created, it is made openly available via the online ISC Bulletin (http://www.isc. ac.uk/iscbulletin/, last access: April 2019). Secondly, the ISC analysts manually review ( 2 or 3 years behind real time) the collected station readings and hypocentre solutions for seis- mic events larger than approximately 3.5 . If all conditions are met (details at http://www.isc.ac.uk/iscbulletin/review/, last access: April 2019), the ISC also recomputes location and magnitude (currently only MS and mb) by combining all the available phase arrival times and amplitude measurements, respectively. ISC location and magnitude procedures have recently been improved (Bondár and Storchak, 2011).

The ISC aims to increase the number of collected bulletins from national data centres or other sources (Willemann and Storchak, 2001) and improve its procedures in earthquake location and magnitude determinations (e.g. Bondár and Storchak, 2011; Di Giacomo and Storchak, 2015; Weston et al., 2018). As a result, the ISC Bulletin has proved to be a very useful resource for seismologists and geoscientists in general, as demonstrated by the vast use of ISC datasets in many research papers, including works on new tomographic models and global tectonics (e.g. Kennett et al., 1995; Rezapour and Pearce, 1998; Bormann et al., 2009; Hayes et al., 2012; Adam and Romanowicz, 2015; Zhan and Kanamori, 2016; Euler and Wysession, 2017; Lay et al., 2017). Recently the ISC has started to compute its own focal mechanisms (freely 
available in the reviewed bulletin) by using first motion polarities both from reported bulletins and picked automatically from waveform data (Lentas, 2017). In addition, the ISC Bulletin contains a substantial number of source mechanisms (Fig. 1) calculated using different data and techniques as reported from various agencies working at local/regional and/or global scales, predominantly covering the period from the mid 1970s till present.

In this paper, we aim to emphasize the availability of source mechanisms in the ISC Bulletin and discuss the different features of those solutions, aiming at helping ISC data users to decide how best to use the database according to the needs of their research.

\section{Source mechanism contributions to the ISC Bulletin}

There are currently 65 agencies in the ISC Bulletin which have reported in the past or continue to report source mechanism solutions to the ISC (Fig. 2). By using the term "source mechanisms" we refer to both moment tensor solutions (and their associated best-fitting double couple mechanisms) and pure double couple mechanisms of a point source. Table 1 shows details of the type of reported source mechanism solutions by each agency.

Major contributors of global source mechanisms include the Global Centroid Moment Tensor Project (GCMT, https: //www.globalcmt.org/, last access: April 2019 Dziewonski et al., 1981; Ekström et al., 2012), the US National Earthquake Information Center (NEIC, or NEIS prior to 1984), and, for regional earthquakes, the National Research Institute for Earth Science and Disaster Resilience (NIED) in Japan and the Pacific Northwest Seismic Network (PNSN).

Note that prior to data year 2006 the HRVD agency code (Harvard University) was used throughout the ISC Bulletin for GCMT solutions. Here we use a unique agency code for these source mechanisms and replace the HRVD agency code with the GCMT code throughout the ISC Bulletin. This is already done for the time period 1976-1979 covered by the first part of the ISC rebuild project (1964-1979, Storchak et al., 2017). After completion of the ISC rebuild project, all remaining HRVD source mechanism solutions will be available under the GCMT code. Moreover, moment tensor solutions for 76 intermediate depth earthquakes and 104 deep earthquakes from 1962 to 1976 have been added under the GCMT agency code (Chen et al., 2001; Huang et al., 1997).

Starting in the mid 1990s, numerous other agencies, mainly national data centres, started reporting source mechanism solutions to the ISC. This has resulted in a steep increase in available mechanism solutions in the ISC Bulletin (Fig. 1). Nevertheless, the coverage and completeness of seismic events with associated source mechanisms are not uniform and primarily depend on the tectonics and the as- sociated seismicity in different regions, the station coverage, and the practices of the reporting agencies (Fig. 3).

In May 2018 the ISC published in the online ISC Bulletin its first automatic focal mechanism solutions obtained from reported first motion polarities and automatic picks of waveform data. These are focal mechanisms for reviewed and relocated earthquakes in the Reviewed ISC Bulletin with $m_{\mathrm{b}}^{\mathrm{ISC}} \geq 4.5$, starting from data month January 2011 . Since then new focal mechanisms have routinely been added for every data month added in the Reviewed ISC Bulletin. Moreover, we have published focal mechanism solutions obtained from reported polarities for the ISC-relocated earthquakes $\left(m_{\mathrm{b}}^{\text {ISC }}>3.5\right)$ covering the time period 1964-1984 as part of the rebuild project (Storchak et al., 2017) and focal mechanism solutions obtained from reported polarities in the ISS (1938-1963) Bulletins (see http://www.isc.ac.uk/ projects/focalmechs/, last access: April 2019). The gap currently shown in Fig. 2 between 1985 and 2010 is expected to be bridged gradually until the completion of the rebuild project.

Figure 4 shows the geographical and magnitude distribution of earthquakes with source mechanisms reported by the agencies which systematically send their mechanism solutions to the ISC (see also Fig. 2 for numbers of reported source mechanisms by agency and distribution in time). Local agencies are important to complement the results of global agencies as they cover events with lower magnitudes. For example, GCMT computes source mechanisms for global earthquakes with magnitude 5.0 and above, but also slightly lower $(\sim 4.5)$ depending on the area and station coverage. Similarly, NEIC covers earthquakes with a minimum magnitude of $M_{\mathrm{W}} \sim 4.5$ on a global scale. IPGP reports earthquakes with magnitude $M_{\mathrm{W}}=5.5$ and above, whilst at the ISC we attempt to determine the focal mechanisms of earthquakes with $m_{\mathrm{b}} \geq 4.5$. On the other hand, agencies like JMA and NIED cover a much wider magnitude range together, in comparison to global agencies, offering a more complete coverage in earthquake source mechanisms for Japan. Similar observations can be drawn for agencies BRK, ECX, and PNSN covering the seismicity along the western coast of the United States, several European agencies (e.g. MED-RCMT and ZUR-RMT) covering the seismicity of Europe, and agencies RSNC and WEL for Colombia and New Zealand, respectively. This obviously introduces some heterogeneity into the available solutions for different areas and for different magnitude ranges, as a result of the different techniques applied by different agencies for the determination of their source models. Moreover, different agencies report different types of source mechanism and associated parametric data (nodal planes, moment tensor components, principal axes - see also Table 1 for details). More details will be given in Sect. 3 .

All the available source mechanisms are included in the ISC Bulletin. However, users particularly interested in focal mechanisms can search using either a dedicated tool 
Table 1. Agencies reporting source mechanism solutions at the ISC for the time period from January 1964 to December 2018 . The cross symbol (X) denotes the type of parametric data that is reported from each agency to the ISC.

\begin{tabular}{|c|c|c|c|c|c|c|}
\hline Agency code & Name & Country & $\begin{array}{r}\text { Magnitude } \\
\text { range }\end{array}$ & $\begin{array}{l}\text { Nodal } \\
\text { planes }\end{array}$ & $\begin{array}{l}\text { Moment } \\
\text { tensor }\end{array}$ & $\begin{array}{l}\text { Principal } \\
\text { axes }\end{array}$ \\
\hline AEIC & Alaska Earthquake Information Center & USA & $3.6-5.0$ & & $\mathrm{X}$ & \\
\hline AFAR & The Afar Depression: Interpretation of the 1960-2000 Earthquakes & Israel & $3.8-6.6$ & $\mathrm{X}$ & & \\
\hline ATA & The Earthquake Research Center Ataturk University & Turkey & $3.9-4.5$ & $\mathrm{X}$ & & \\
\hline ATH & National Observatory of Athens & Greece & $3.7-5.5$ & $\mathrm{X}$ & & \\
\hline BER & University of Bergen & Norway & $1.1-4.0$ & $\mathrm{X}$ & & \\
\hline BGS & British Geological Survey & United Kingdom & $1.2-4.6$ & $\mathrm{X}$ & & \\
\hline BRK & Berkeley Seismological Laboratory & USA & $2.9-7.2$ & $\mathrm{X}$ & & \\
\hline BUD & Geodetic and Geophysical Research Institute & Hungary & $2.0-4.7$ & $\mathrm{X}$ & $\mathrm{X}$ & $\mathrm{X}$ \\
\hline CASC & Central American Seismic Center & Costa Rica & $3.1-6.5$ & $\mathrm{X}$ & & \\
\hline DNK & Geological Survey of Denmark and Greenland & Denmark & $2.5-4.6$ & $\mathrm{X}$ & & \\
\hline ECX & Centro de Investigación Científica y de Educación Superior de Ensenada & Mexico & $0.9-5.8$ & $\mathrm{X}$ & & \\
\hline FUNV & Fundación Venezolana de Investigaciones Sismológicas & Venezuela & $1.9-4.2$ & $\mathrm{X}$ & & \\
\hline GBZT & Marmara Research Center & Turkey & $3.7-5.4$ & $\mathrm{X}$ & & \\
\hline GCMT & The Global CMT Project & USA & $4.0-9.1$ & $\mathrm{X}$ & $\mathrm{X}$ & $\mathrm{X}$ \\
\hline GRAL & National Council for Scientific Research & Lebanon & $1.4-3.3$ & $\mathrm{X}$ & & \\
\hline GTFE & German Task Force for Earthquakes & Germany & $2.2-4.6$ & $\mathrm{X}$ & & \\
\hline GUC & Centro Sismológico Nacional, Universidad de Chile & Chile & $2.9-4.3$ & $\mathrm{X}$ & & \\
\hline HLW & National Research Institute of Astronomy and Geophysics & Egypt & $2.5-4.9$ & $\mathrm{X}$ & & $\mathrm{X}$ \\
\hline HYB & National Geophysical Research Institute & India & $3.0-3.8$ & $\mathrm{X}$ & & \\
\hline IAG & Instituto Andaluz de Geofisica & Spain & $3.2-6.8$ & $\mathrm{X}$ & $\mathrm{X}$ & $\mathrm{X}$ \\
\hline IEC & Institute of the Earth Crust, SB RAS & Russia & $3.3-6.3$ & $\mathrm{X}$ & & $\mathrm{X}$ \\
\hline INET & Instituto Nicaraguense de Estudios Territoriales - INETER & Nicaragua & $3.5-6.0$ & $\mathrm{X}$ & & \\
\hline IPGP & Institut de Physique du Globe de Paris & France & $5.2-8.2$ & $\mathrm{X}$ & & \\
\hline ISC & International Seismological Centre & United Kingdom & $3.6-9.1$ & $\mathrm{X}$ & & $\mathrm{X}$ \\
\hline ISN & Iraqi Meteorological and Seismology Organisation & Iraq & 5.0 & $\mathrm{X}$ & & \\
\hline JMA & Japan Meteorological Agency & Japan & $1.6-8.3$ & $\mathrm{X}$ & & $\mathrm{X}$ \\
\hline JSN & Jamaica Seismic Network & Jamaica & $2.5-5.2$ & $\mathrm{X}$ & & \\
\hline LDO & Lamont-Doherty Earth Observatory & USA & $3.5-4.6$ & $\mathrm{X}$ & $\mathrm{X}$ & \\
\hline MED RCMT & MedNet Regional Centroid - Moment Tensors & Italy & $3.6-6.9$ & $\mathrm{X}$ & $\mathrm{X}$ & $\mathrm{X}$ \\
\hline MEX & Instituto de Geofísica de la UNAM & Mexico & $2.9-7.0$ & $\mathrm{X}$ & & \\
\hline MOS & Geophysical Survey of Russian Academy of Sciences & Russia & $5.1-9.1$ & $\mathrm{X}$ & & $\mathrm{X}$ \\
\hline NAO & Stiftelsen NORSAR & Norway & 2.5 & $\mathrm{X}$ & & \\
\hline NCEDC & Northern California Earthquake Data Center & USA & $3.0-5.2$ & & $\mathrm{X}$ & \\
\hline NDI & National Centre for Seismology of the Ministry of Earth Sciences of India & India & $3.5-7.7$ & $\mathrm{X}$ & & \\
\hline NEIC & National Earthquake Information Center & USA & $2.4-9.1$ & $\mathrm{X}$ & $\mathrm{X}$ & $\mathrm{X}$ \\
\hline NEIS & National Earthquake Information Service & USA & $5.3-7.7$ & $\mathrm{X}$ & $\mathrm{X}$ & $\mathrm{X}$ \\
\hline NIED & National Research Institute for Earth Science and Disaster Prevention & Japan & $3.1-9.1$ & $\mathrm{X}$ & $\mathrm{X}$ & \\
\hline NSSC & National Syrian Seismological Center & Syria & $1.6-4.6$ & $\mathrm{X}$ & & \\
\hline OSPL & Observatorio Sismologico Politecnico Loyola & Dominican Republic & $2.2-5.8$ & $\mathrm{X}$ & & \\
\hline OTT & Canadian Hazards Information Service, Natural Resources Canada & Canada & $3.6-7.8$ & $\mathrm{X}$ & & \\
\hline PAS & California Institute of Technology & USA & $3.3-7.2$ & $\mathrm{X}$ & $\mathrm{X}$ & $\mathrm{X}$ \\
\hline PGC & Pacific Geoscience Centre & Canada & $3.5-6.6$ & $\mathrm{X}$ & $\mathrm{X}$ & $\mathrm{X}$ \\
\hline PNSN & Pacific Northwest Seismic Network & USA & $0.0-6.8$ & $\mathrm{X}$ & & $\mathrm{X}$ \\
\hline PRE & Council for Geoscience & South Africa & $2.2-6.5$ & $\mathrm{X}$ & & \\
\hline REN & MacKay School of Mines & USA & $3.3-4.2$ & & $\mathrm{X}$ & \\
\hline ROM & Istituto Nazionale di Geofisica e Vulcanologia & Italy & $3.1-6.6$ & $\mathrm{X}$ & $\mathrm{X}$ & \\
\hline RSNC & Red Sismológica Nacional de Colombia & Colombia & $1.6-6.3$ & $\mathrm{X}$ & & \\
\hline SEA & Geophysics Program AK-50 & USA & $3.2-3.3$ & & $\mathrm{X}$ & \\
\hline SJA & Instituto Nacional de Prevención Sísmica & Argentina & $2.6-5.9$ & $\mathrm{X}$ & & \\
\hline SLM & Saint Louis University & USA & $2.2-6.0$ & $\mathrm{X}$ & $\mathrm{X}$ & $\mathrm{X}$ \\
\hline SNET & Servicio Nacional de Estudios Territoriales & El Salvador & $1.3-5.6$ & $\mathrm{X}$ & & \\
\hline SSS & Centro de Estudios y Investigaciones Geotecnicas del San Salvador & El Salvador & $3.6-6.0$ & $\mathrm{X}$ & & \\
\hline THE & Department of Geophysics, Aristotle University of Thessaloniki & Greece & $4.2-6.1$ & $\mathrm{X}$ & & \\
\hline THR & International Institute of Earthquake Engineering and Seismology (IIEES) & Iran & $4.5-6.1$ & $\mathrm{X}$ & & \\
\hline TUL & Oklahoma Geological Survey & USA & $2.9-3.7$ & & $\mathrm{X}$ & \\
\hline UAF & Department of Geosciences & USA & $0.5-5.2$ & $\mathrm{X}$ & $\mathrm{X}$ & \\
\hline UCDES & Department of Earth Sciences & UK & $5.5-6.7$ & $\mathrm{X}$ & & \\
\hline UCR & Sección de Sismología, Vulcanología y Exploración Geofísica & Costa Rica & $2.6-6.0$ & $\mathrm{X}$ & & \\
\hline UESG & School of Geosciences & UK & $5.7-6.2$ & $\mathrm{X}$ & & \\
\hline UPA & Universidad de Panama & Panama & $1.8-6.6$ & $\mathrm{X}$ & & \\
\hline UPIES & Institute of Earth and Environmental Science & Germany & $4.3-6.4$ & $\mathrm{X}$ & $\mathrm{X}$ & \\
\hline UPSL & University of Patras, Department of Geology & Greece & $3.3-6.8$ & $\mathrm{X}$ & & \\
\hline USGS & United States Geological Survey & USA & $3.2-7.8$ & $X$ & $\mathrm{X}$ & $\mathrm{X}$ \\
\hline UUSS & The University of Utah Seismograph Stations & USA & $3.3-3.8$ & & $\mathrm{X}$ & \\
\hline WEL & Institute of Geological and Nuclear Sciences & New Zealand & $3.4-7.1$ & $\mathrm{X}$ & & $\mathrm{X}$ \\
\hline ZUR RMT & Zurich Moment Tensors & Switzerland & $2.8-7.6$ & $\mathrm{X}$ & $\mathrm{X}$ & $\mathrm{X}$ \\
\hline
\end{tabular}



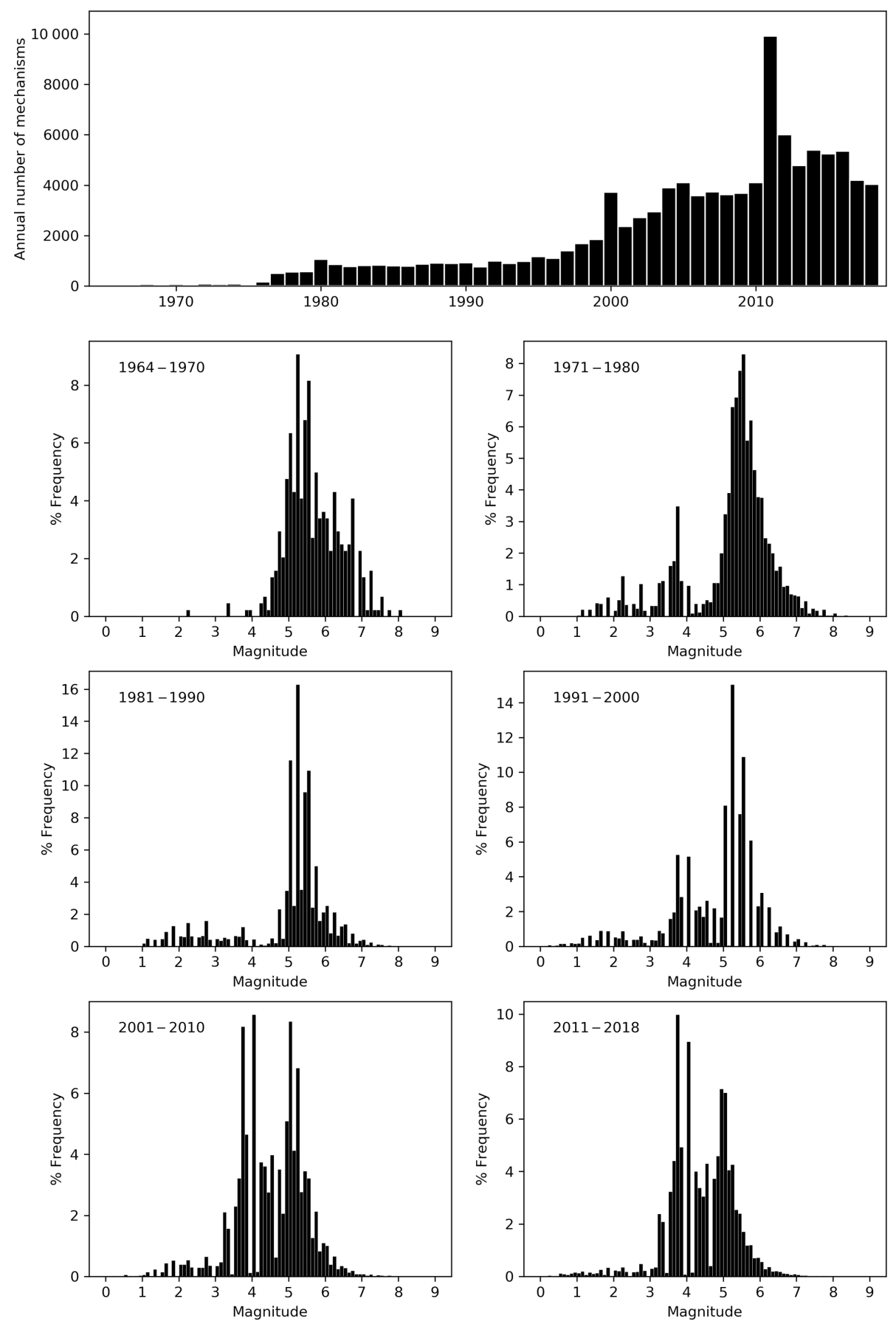

Figure 1. Number of source mechanisms in the ISC Bulletin from January 1964 to December 2018 and normalized frequency-magnitude distributions with respect to different time periods. A magnitude value for each event with an associated source mechanism is selected following the scheme described in Di Giacomo and Storchak (2015). Note the high peak in the top subplot in 2011 which is associated with the 2011 Tohoku earthquake aftershock sequence. A slight dip for year 2018 is only apparent as the data collection is not yet complete.

at http://www.isc.ac.uk/iscbulletin/search/fmechanisms/ (last access: April 2019) or web services at http://www.isc. ac.uk/iscbulletin/search/webservices/fmechanisms/ (last access: April 2019). Search parameters include date, area, magnitude, depth, and agency code. Search outputs are available either in a comma-separated CSV-like format with one line per mechanism solution or in QuakeML format. Included in the output are the ISC event identifier, scalar moments, moment tensor components, nodal planes, principal axes, and the hypocentre/centroid parameters for each mechanism 


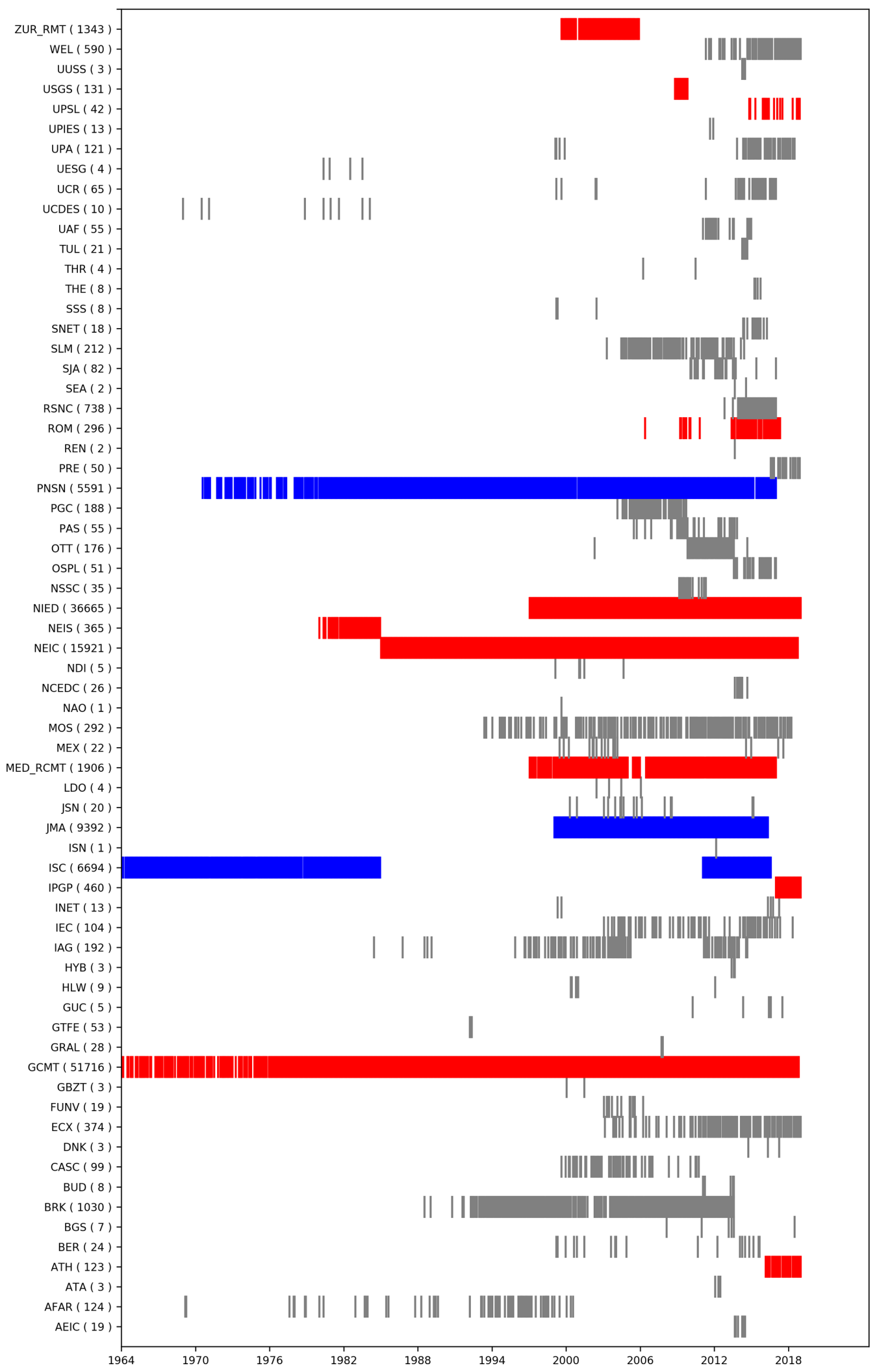

Figure 2. Time distribution of source mechanisms in the ISC Bulletin (January 1964-December 2018) reported by different agencies. The numbers in brackets next to each agency code show the total number of reported source mechanism solutions. Red lines indicate waveform inversion techniques, blue lines indicate first motion polarity techniques, and grey colour shows cases where there is no information available on the techniques being used or we could not verify them. A detailed list of the reporting agencies is shown in Table 1 . 

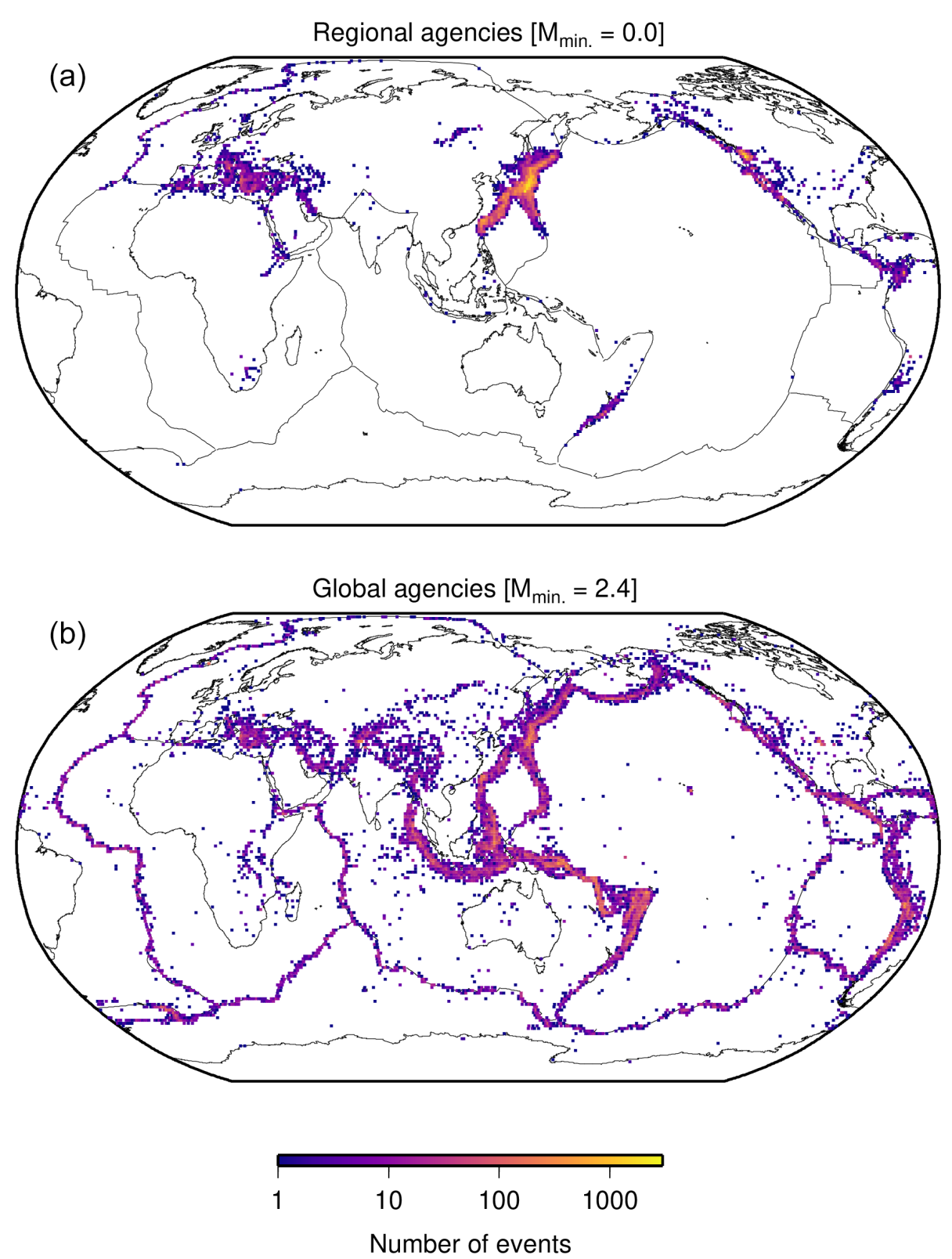

Figure 3. Global maps showing the number of events with at least one source mechanism reported in the ISC Bulletin for the time period from January 1964 to December 2018 , in a $1^{\circ}$ by $1^{\circ}$ grid, for mechanism solutions reported by local and regional agencies (a), and global agencies (b, (GCMT, HRVD, IPGP, ISC, MOS, NEIC, NEIS)). The minimum magnitude $\left(M_{\min }\right.$.) following the scheme described in Di Giacomo and Storchak (2015) is shown on top of each map.

solution, where applicable. The format is explained in detail at http://www.isc.ac.uk/iscbulletin/search/fmechanisms/ csvoutput/ (last access: April 2019).

\section{Source mechanism variability}

The majority of the observed global seismicity is characterized by crustal (shallow) earthquakes which occur as a result of a sudden release of accumulated strain across a seismic fault of finite dimensions. A seismic source whose en- ergy is recorded at stations located at distances of several wavelengths from the source can be approximated as a point source. The point source model provides a simple and convenient approach in order to simulate the seismic radiation. Nonetheless, for larger earthquakes (for example mega-thrust earthquakes, Tsai et al., 2005; Lentas et al., 2014; Ye et al., 2016), and/or earthquakes observed at distances close to the source (a few kilometres), the point source approximation is not sufficient, and ideally, the rupture propagation history and finite fault characteristics should be taken into account 

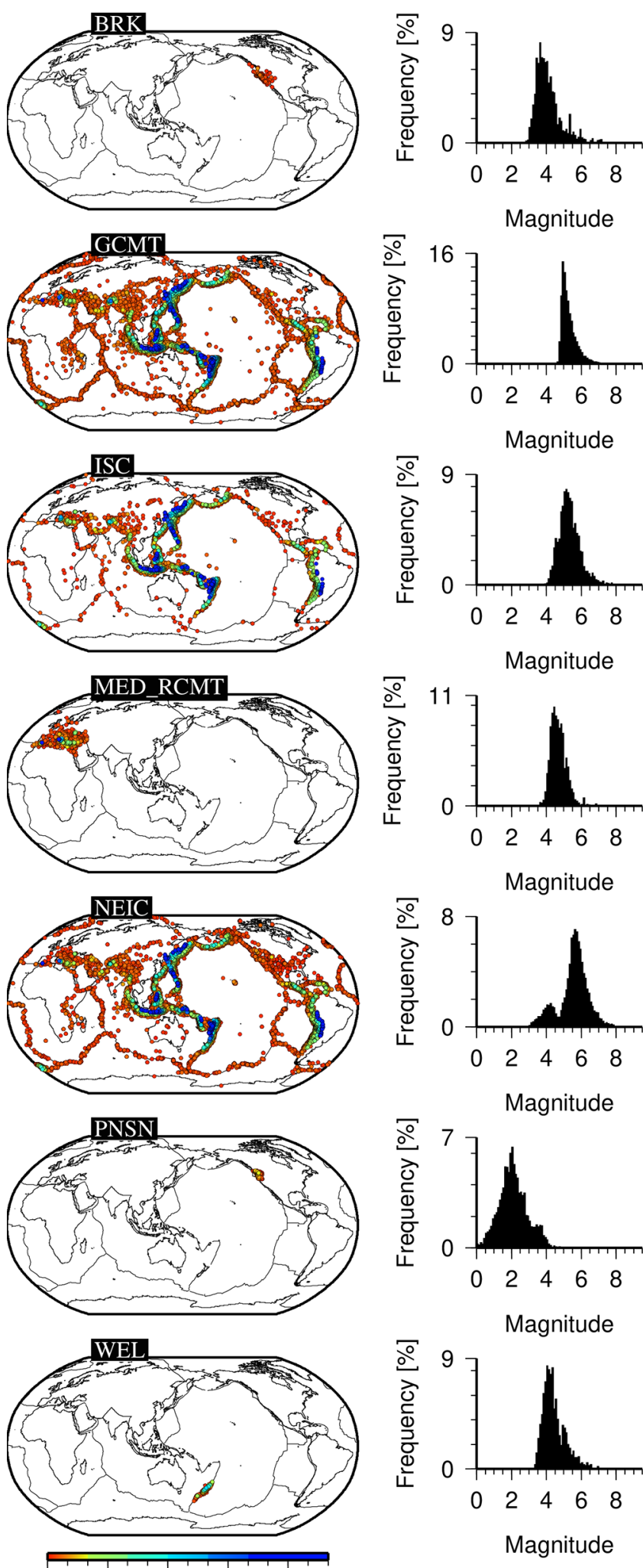

$\begin{array}{lllll}0 & 150 & 300 & 450 & 600\end{array}$

Depth $[\mathrm{km}]$

Magnitude

Magnitude

Magnitude
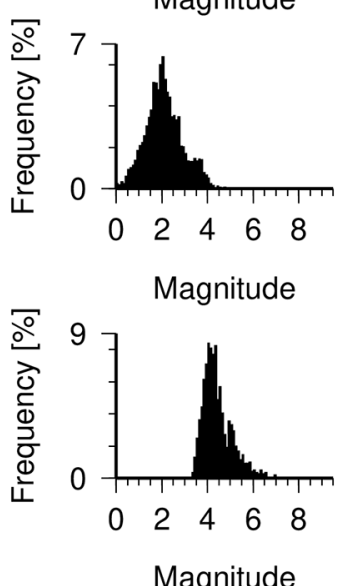
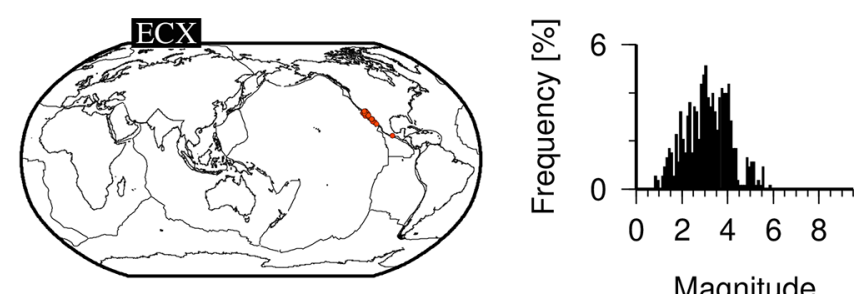

Magnitude
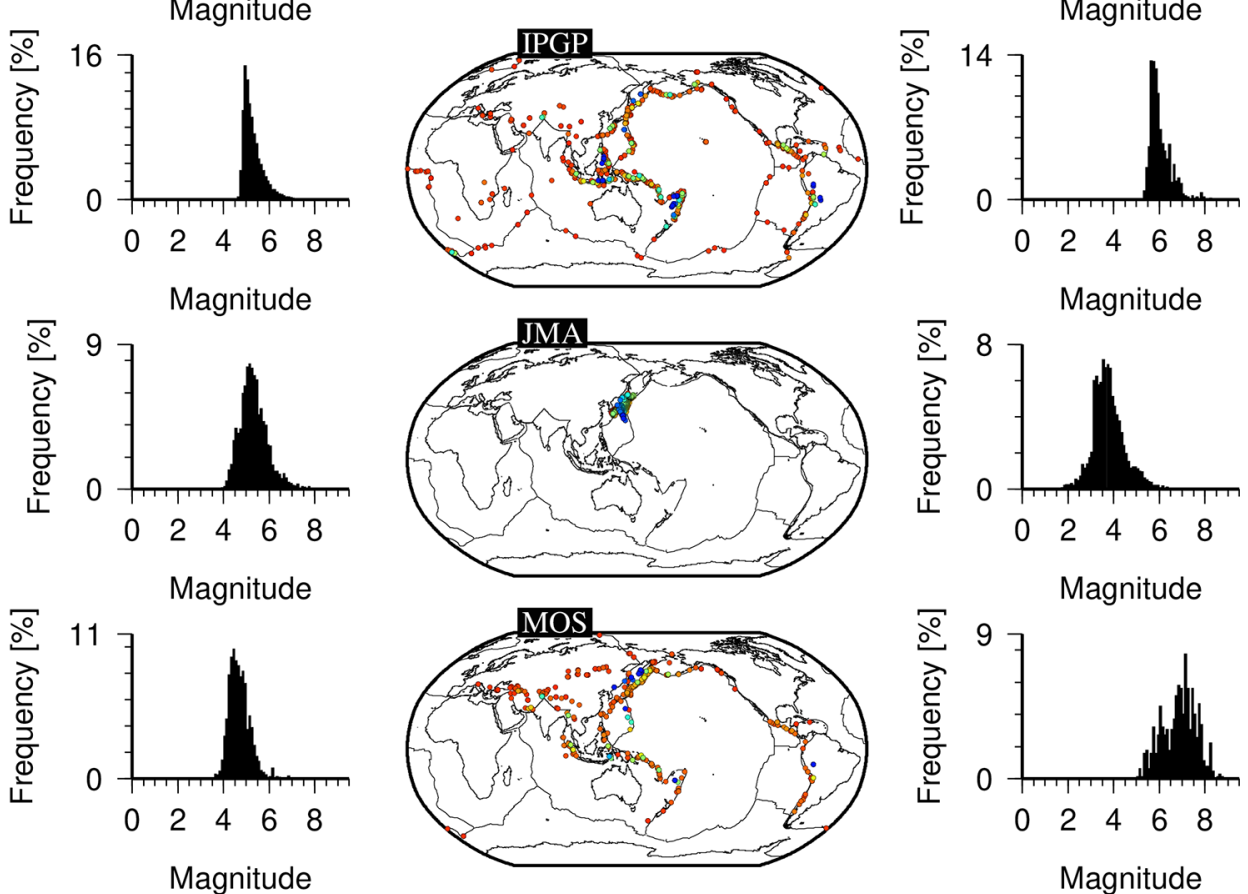

Magnitude
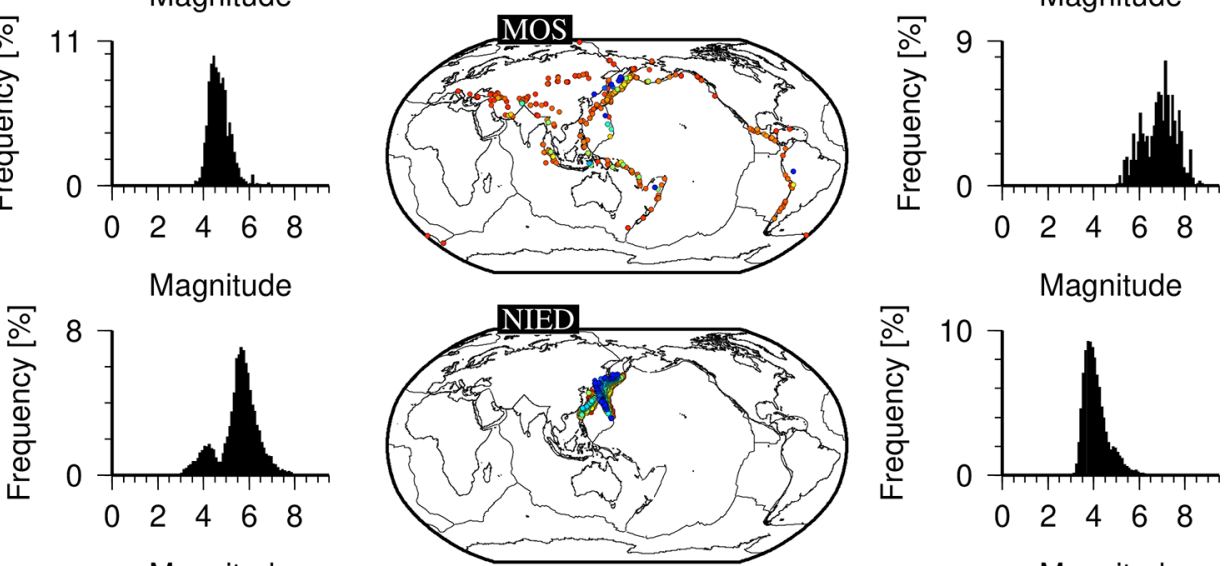

Magnitude
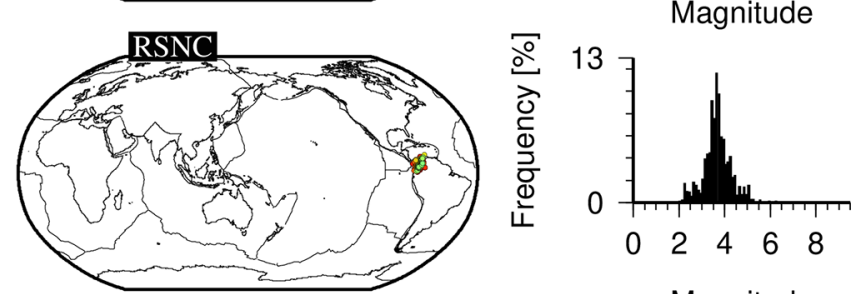

Magnitude
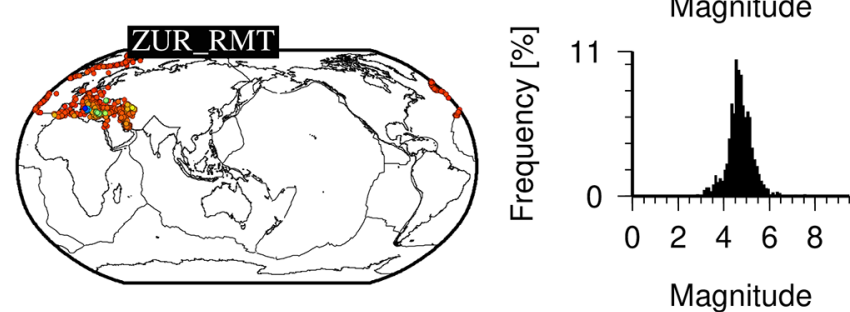

Figure 4. Geographical and frequency-magnitude distribution (following the scheme described in Di Giacomo and Storchak (2015)) of earthquakes with source mechanisms reported by the agencies which systematically send their mechanism solutions to the ISC. Locations on the maps are colour-coded by depth. The agency codes are shown on top of each map and their details can be found in Table 1. 
when attempting to model the seismic source. For deep earthquakes, on the other hand, non-conventional models have been proposed (e.g. Okal, 2001; Meng et al., 2014), but the point source approximation is also being used for the sake of simplicity and processing consistency with crustal (shallow) earthquakes.

A seismic point source is described in principle by a double couple system of equivalent body forces which are represented by two unit vectors, the normal and slip vectors. These vectors are defined by the orientation of the fault and the direction of slip in terms of the strike, dip, and rake angles (e.g. Aki and Richards, 2002). Different techniques follow different concepts for determining the source model of a point source. Some algorithms solve directly for the geometry of a planar fault, meaning the strike, dip, and rake of the fault and auxiliary planes assuming a pure double couple mechanism. Other techniques determine the six components of the moment tensor. This is a mathematical representation of the equivalent body forces acting on a seismic point source, and can be decomposed into an isotropic component, a compensated linear vector dipole (CLVD), and a best-fitting double couple mechanism describing the geometry of a planar fault.

Source mechanism solutions can be determined by using two main data types: (i) parametric data such as first motion P-wave polarities and amplitude ratios and (ii) waveform data modelling. A vast variety of techniques and algorithms have been developed over the last few decades using different concepts and data. The most robust results are obtained by waveform modelling methods. Even though techniques based on polarities depend strongly on the network geometry and the station azimuthal coverage, they can still be very useful in determining the focal mechanisms of small earthquakes and aftershock sequences using local networks (Shearer, 1998).

Focal mechanisms expressed in terms of strike, dip, and rake angles, based on first motion polarities are reported for example by JMA (Nakamura and Mochizuki, 1988), PNSN (FPFIT code by Reasenberg and Oppenheimer, 1985), and ISC (Lentas, 2017). They depend on pre-determined locations and reflect the geometry of the seismic fault at the initial breaking of the rupture. Waveform modelling techniques on the other hand usually consider a group of phases (body waves and/or surface waves) and provide source mechanisms closer to the dominant component of the entire rupture geometry. Their source models can be expressed as strike, dip, and rake angles or moment tensor components, and they can either be based on a pre-determined location or can be centroid solutions. Centroid-based techniques determine the six elements of the moment tensor, the centroid location (latitude, longitude, and depth of a point source), and the origin time simultaneously. Waveform modelling methods such as the SCARDEC technique (Vallée et al., 2010), whose source models are reported to the ISC by agency IPGP, make use of body-wave phases and the NEIC location. The obtained source models are expressed as strike, dip, and rake angles of a pure double couple source. Source models of other waveform modelling techniques based on a predetermined hypocentre location are also routinely reported in the ISC Bulletin, such as the NIED solutions for the Japanese area (Fukuyama and Kawai, 1998). In this case the reported source models are expressed in terms of the six elements of the moment tensor and the best-fitting double couple solution. Centroid-based techniques like the GCMT (Dziewonski et al., 1981; Ekström et al., 2012), MED-RCMT (Pondrelli et al., 2011), ZUR-RMT (Braunmiller et al., 2002), and others applied by the NEIC (Hayes et al., 2009; Benz and Herrmann, 2014) provide centroid locations, moment tensor components, and best-fitting double couple solutions.

Source models for all the above-mentioned techniques can be found in the ISC Bulletin (see Fig. 2). Moreover, taking into consideration additional differences in velocity models, station distribution, and observations in different waveform frequency bands that are being used by different techniques, some variation among source mechanisms reported by different agencies for the same seismic event is to be expected.

Figure 5 shows the frequency distribution of available source mechanism solutions per event in the ISC Bulletin and the frequency distribution of maximum intra-event rotation angles for the events with at least two reported mechanism solutions. The rotation angle describes the transformation of a double couple mechanism into another arbitrary mechanism through 3-D rotations (Kagan, 1991). To further visualize this, it is worth noting that the rotation angle between two double couple mechanism solutions can vary between 0 and $120^{\circ}$, where $0^{\circ}$ corresponds to a perfect match and $120^{\circ}$ describes an absolute mismatch, which physically translates into mechanism solutions showing for example perpendicular strike orientations and/or conflicting fault types (e.g. normal compared to thrust or normal compared to pure strike-slip). Consequently, in order to determine the maximum intra-event rotation angle, we list all the available best-fitting double couple source mechanism solutions for each event, and we calculate rotation angles for all possible pairs. We then pick the maximum value as describing the greatest mismatch between the available mechanisms and hence the extent of expected differences in strike, dip, and rake (see for example Fig. 1 in Cesca et al., 2013).

A substantial number of earthquakes in the ISC Bulletin $(\sim 40 \%)$ show intra-event rotation angles between 10 and $25^{\circ}$ (see Fig. 5). Cases showing large differences, above $40^{\circ}$, occasionally occur and can be partly explained by earthquakes showing complex rupture, such as the 3 November 2002, $M_{\mathrm{W}}=7.9$, Denali Central Alaska earthquake (e.g. Ozacar et al., 2003) and the doublet 7 December 2012, $M_{\mathrm{W}}=7.2$, eastern coast of Honshu earthquake (e.g. Lay et al., 2013), which show intra-event rotation angles up to 60 and $90^{\circ}$, respectively, or comparing automatic source mechanism solutions such as the 25 May 2015, $M_{\mathrm{W}}=5.2$, eastern Honshu earthquake which shows intra-event rotation angles up to $\sim 90^{\circ}$. 

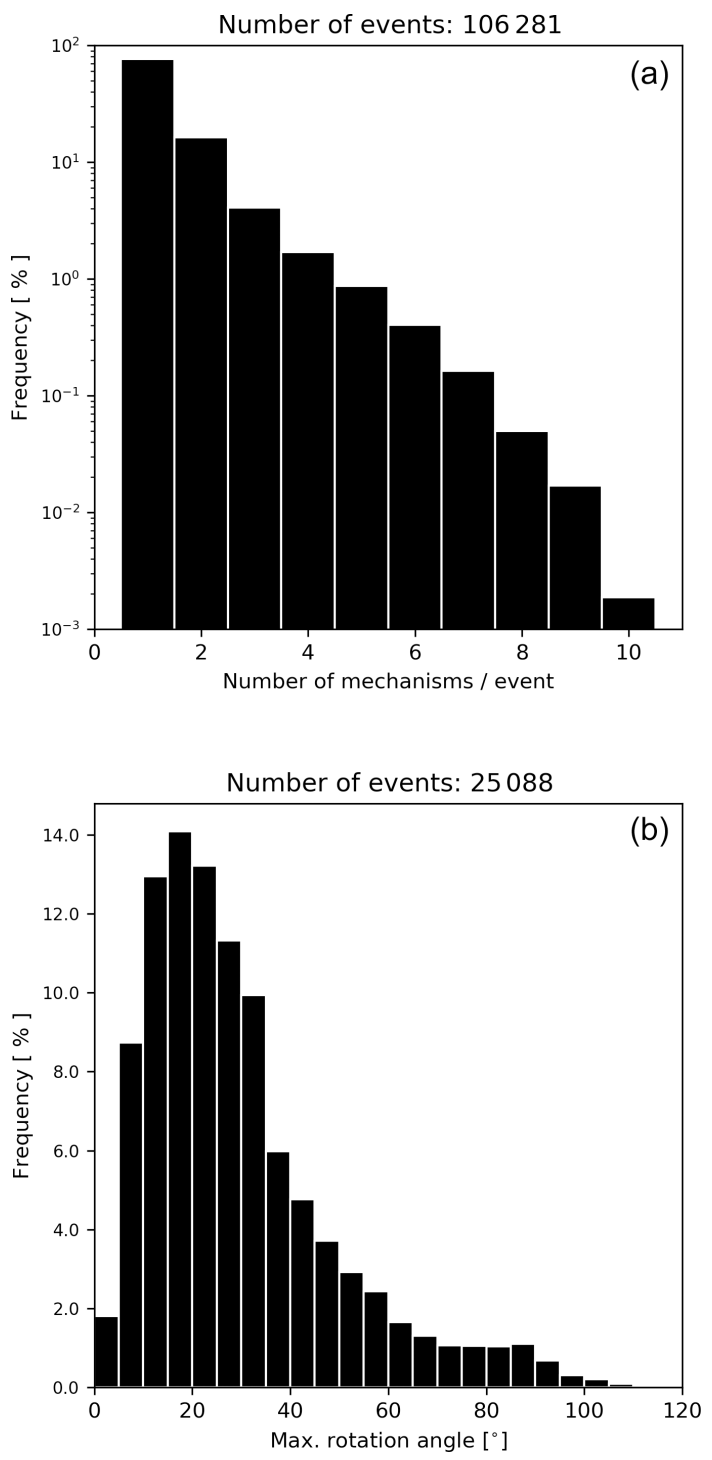

Figure 5. Frequency distribution of available source mechanisms per event in the ISC Bulletin for the time period from January 1964 to December 2018 (a) and intra-event maximum rotation angle frequency distribution for the seismic events with at least two mechanism solutions available (b).

In the case of the Denali event (http://www.isc.ac. uk/cgi-bin/web-db-v4?event_id=6123395\&out_format=

IMS1.0\&request=COMPREHENSIVE, last access: April 2019), the earthquake started as a thrust event and then ruptured along the curved strike-slip Denali fault (Ozacar et al., 2003). Similarly, Lay et al. (2013) suggested the case of a doublet event that began with a $M_{\mathrm{W}}=7.2$ thrust earthquake (http://www.isc.ac.uk/cgi-bin/ web-db-v4?event_id=607215270\&out_format=IMS1 .

0\&request=COMPREHENSIVE, last access: April 2019) and was followed by a $M_{\mathrm{W}}=7.1-7.2$ normal-faulting earthquake (http://www.isc.ac.uk/cgi-bin/web-db-v4?
event_id=602005586\&out_format=IMS1.0\&request= COMPREHENSIVE, last access: April 2019) for the case of the 2012 eastern coast of Honshu earthquake. Since the routinely reported mechanism solutions for these complex events are based on the point source approximation, it is no surprise that different episodes of rupture are captured by different methods using different data. For example, the Global CMT, by mainly using long-period surface waves (and in some cases long-period body waves), has detected the strike-slip nature of the Denali earthquake. In contrast, the NEIC source mechanism captured the initial stage of the rupture and shows evidence of thrust faulting. Note that large intra-event rotation angles can occur also for moderate earthquakes, such as for the 25 May 2015, $M_{\mathrm{W}}=5.2$, eastern Honshu earthquake. Indeed, for this event the intra-event rotation angles are up to $\sim 90^{\circ}$. It is likely that such variability is due to differences in the methods and data applied (first motion by JMA and ISC versus waveform modelling by NIED and GCMT) rather than to rupture complexity. Substantial intra-event differences are also very common as a result of multiple solutions reported by the PNSN for small earthquakes with poorly constrained source mechanisms, such as the 11 February $1981, M_{\mathrm{d}}=2.5$, Washington earthquake where the maximum intra-event rotation angle can be as high as $100^{\circ}$. This is very common in the case of PNSN-reported mechanisms due to the first motion technique that is being used which provides multiple solutions if the data are not adequate for the determination of a single well-constrained solution. Quality characterization found in the comments in the online ISC Bulletin can help users to identify the most robust mechanism solution among multiple PNSN-provided mechanisms for the same event.

Intra-event rotation angles are not currently calculated and published in a systematic way in the ISC Bulletin, and hence, the identification of cases of substantial differences in reported source models is not part of the ISC standard procedures. Researchers who are interested in earthquake source model validations and assessment are encouraged to make use of the ISC Bulletin for this purpose and apply their own schemes. As already mentioned, the source models in the ISC Bulletin are not reviewed by the analysts. However, we frequently carry out health checks of the bulletin, namely, removing duplicates and checking for consistency between moment tensors and best-fitting double couple solutions, or moment tensors and principal axes, or double couple solutions and principal axes, and so on. This has resulted in correction of a few cases (less than $1 \%$ of the entire bulletin) where either typos from the data providers or bugs in the database parsing algorithms have been identified and fixed. As part of this process we did not detect systematic inconsistencies between source models provided by different agencies for the same seismic event that has to do with the type of source mechanism, or depth, or a specific region. The most common case in this respect is source mechanisms provided by PNSN for small magnitude events along the western coast 
of the United States due to the type of methodology that is being applied which determines multiple solutions when the data quality is poor.

Source mechanisms are also used in a variety of studies (e.g. tectonics, stress patterns, cluster analysis) aiming at characterizing an event or a set of events by the fault style. Several classifications of fault styles are available in the literature (see e.g. Célérier, 2010, for an overview). For this work we adopt the classification proposed by Zoback (1992) for the World Stress Map Project (http://www.world-stress-map. org/, last access: April 2019). With such classification an event is assigned one of the following fault styles: thrust, normal, strike-slip, normal with strike-slip component, thrust with strike-slip component, and undefined for events not fitting into any of the previous categories (similarly to the "odd" group in Frohlich, 1992). Figure 6 shows the annual number of earthquakes grouped according to Zoback (1992) and the sole intent of the figure is to showcase one of the possible uses for the source mechanisms in the ISC Bulletin.

Considering the source mechanisms in the ISC Bulletin, as discussed so far, it is obvious that for events with only one mechanism available the fault style is easily assigned. The same also applies to events with multiple solutions all of the same fault style (e.g. http://www. isc.ac.uk/cgi-bin/web-db-v4?event_id=3021752\&out_ format=IMS1.0\&request=COMPREHENSIVE, last access: April 2019). However, for events with more than one solution it is not always possible to assign a fault style with the solutions at hand. This happens, for example, when an event has two source mechanisms and one being thrust and the other normal (e.g. http://www. isc.ac.uk/cgi-bin/web-db-v4?event_id=602214316\&out_ format=IMS1.0\&request=COMPREHENSIVE, last access: April 2019). Similarly, if an event has multiple solutions, we may have source mechanisms falling into more than two fault styles (e.g. http://www.isc.ac.uk/cgi-bin/web-db-v4? event_id=602431903\&out_format=IMS1.0\&request= COMPREHENSIVE, last access: April 2019) or without a unique maximum in the number of source mechanisms belonging to a fault style (e.g. http://www.isc.ac.uk/cgi-bin/ web-db-v4?event_id=602945524\&out_format=IMS1 .

0\&request=COMPREHENSIVE, last access: April 2019). In such cases we do not assign a fault style to an event. If, instead, out of the fault style distribution within an event there is a more recurrent fault style (e.g. http://www.isc.ac.uk/ cgi-bin/web-db-v4?event_id=2944860\&out_format=IMS1 .

0\&request=COMPREHENSIVE, last access: April 2019), we still assign a fault style to the event. Therefore, in Fig. 6 we also show the "Discrepant" category for those events where we could not assign a specific fault style. Note that complex earthquakes, such as the ones previously mentioned, may also fall into this category. The annual percentage of events falling into the "Discrepant" category is usually between $0 \%$ and $5 \%$, with a maximum of $8 \%$ in 2000. The occurrence of such "Discrepant" events should

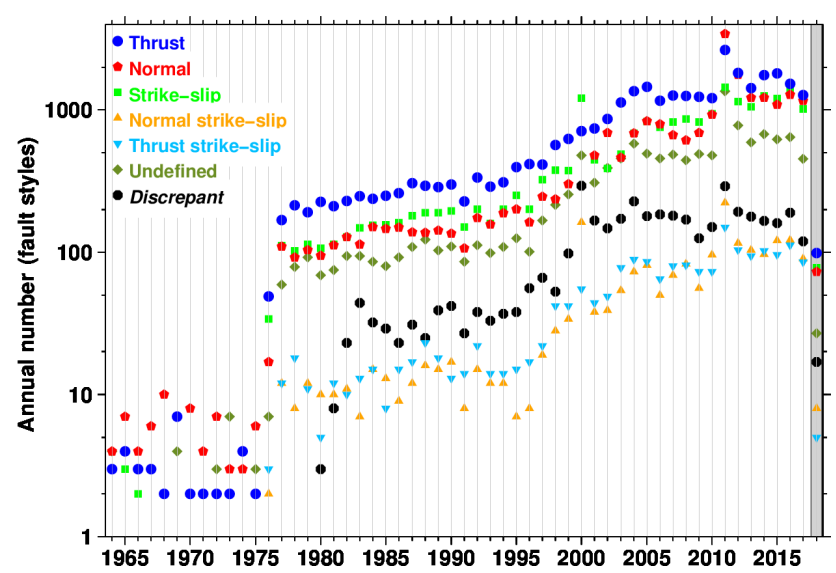

Figure 6. Annual number of source mechanisms grouped by Zoback (1992) fault styles. Dark blue circles, red pentagons, green squares, orange triangles, light blue inverted triangles, and olive diamonds represent, respectively, thrust, normal, strike-slip, normal with strike-slip component, thrust with strike-slip component, and undefined earthquakes. Black octagons are earthquakes for which the intra-variability of the source mechanisms does not allow us to assign an earthquake to a fault style. These are earthquakes with large rotation angles (see Fig. 5). The percentage of such earthquakes goes up to $8 \%$ of earthquakes per year. The grey area for year 2018 denotes that the data collection is not yet complete. See main text for details.

not discourage the use of source mechanisms from the ISC Bulletin. Indeed, this category of events can highlight complex events or events for which more studies are needed.

Not surprisingly, Fig. 6 shows how the thrust earthquakes dominate the annual occurrences, with the only exceptions for year 2000 (significant strike-slip aftershock sequence following the 2000 Tottori, Japan, earthquake) and 2011 (aftershocks of the 2011 Tohoku earthquake, due to the stress field change, were characterized by many normal-fault earthquakes, as shown e.g. by Hasegawa et al., 2012). Such use of the source mechanisms in the ISC Bulletin can be used for event characterizations and applied e.g. to studies concerning regional stress patterns (e.g. Balfour et al., 2011), magnitude (e.g. Lomax and Michelini, 2009), tsunami/tsunamigenic earthquakes (e.g. Okal and Newman, 2001), and other seismological fields.

\section{Data availability}

The earthquake source mechanisms summarized in this work are freely available within the ISC Bulletin websearch at https://doi.org/10.31905/D808B830 (Lentas et al., 2016). All data used in this paper are maintained at the ISC (http: //www.isc.ac.uk/, last access: 15 March 2019). 


\section{Summary and conclusions}

The ISC offers the most comprehensive bulletin of global seismicity in terms of hypocentre solutions, phase arrivals, magnitudes, and amplitude measurements. In this paper we present an additional aspect of the ISC Bulletin, namely its source mechanism content and the opportunity for ISC users to complement the source mechanism information with all other data included in the ISC Bulletin.

The ISC has a mandate to collect as many parametric data as possible from various sources around the world and make it freely available to the seismological as well as broad geoscience communities. As a result, the magnitude range of earthquakes covered by available mechanism solutions is larger than individual global catalogues such as GCMT or NEIC. However, this feature inevitably leads to a higher heterogeneity in the solutions due to different methods adopted by each provider. Thus, users are advised to be aware of the techniques being used in the computations of the various source models in the ISC Bulletin. For example, centroidbased mechanism solutions should be used together with centroid locations, since (i) both the centroid mechanism and centroid location are parts of the same output and (ii) substantial differences may exist among centroid locations and standard hypocentre locations fitting the observed phase arrival times of body waves. To facilitate this the CSV format provided by the online ISC Bulletin indicates whether a mechanism solution is centroid or hypocentre. Source mechanisms obtained from pre-determined standard hypocentre locations can be used together with the provider's hypocentre solution or the prime hypocentre solution in the ISC Bulletin. However, large differences in depth may be present in some cases among the prime hypocentre solution and the solution provided by the mechanism's agency. Moreover, information regarding the quality of the obtained mechanism solutions such as the number of stations being used and/or errors in the obtained source models is also provided in the ISC Bulletin where available from the reporting agency. The latter is more common in moment tensor solutions. Detailed quality information is routinely provided for the ISC focal mechanism solutions, both in the comments section in the online ISC Bulletin as well as by clicking on the "ISC Focal Mechanism" logo on the top of the online bulletin.

In the case of multiple available source mechanism solutions for the same event, the question "which source model should I pick for my research from the ISC Bulletin" arises from a researcher's practical point of view. Since the source model determination problem is not fully resolved and the point source approximation is still the standard in routine earthquake mechanism representation, unfortunately there is no easy and straightforward answer to this question. The purpose of this paper is to give insights into the content of the ISC Bulletin regarding the availability of earthquake source models for seismologists and further highlight the complexity of the earthquake source and the associated point source models for the broad geoscience community. Thus, only general suggestions can be given without attempting or being willing to discriminate the data in the ISC Bulletin into right or wrong. Users of the bulletin should keep in mind that different techniques are based on different data (first motion polarities, body wave amplitude ratios, body/surface wave modelling), and as a result they weight differently various episodes in the rupture history which ultimately can have a strong effect on the final solution. For example, slip takes place across seismic faults that are not necessarily planar, but their orientation can vary with length. Moreover, the use of local/regional or teleseismic data can be another component of source model variations, and in conjunction with the uncertainties in velocity models that are being used to simulate the wave propagation in the Earth's interior it is advisable to take into consideration the details of the methodologies being used by different source mechanism providers.

In all cases, the ISC will not deprecate solutions without being revised by the data provider. The ISC cannot encourage the use of source models of one data provider over another. We try to include as much information as possible in the comments section of the online ISC Bulletin regarding each mechanism solution. Researchers are free to make use of any source models they might think that fit their research, and to facilitate this we advise users to pay attention to quality information provided in the comments section, namely, the number of stations and components being used or the azimuthal gap. Another tool for selecting the most appropriate source model is the association of the mechanism solution with the type of location being used (hypocentre/centroid) as stated above. In this paper we briefly summarized the methods being used by major model reporters. However, users still need to identify the most appropriate source models for their research.

Similar to the variation of hypocentre solutions in the ISC Bulletin, multiple source mechanisms for the same seismic event, when available, can provide a measure of the posterior uncertainties with respect to data errors and modelling techniques. Despite variations in the methods and data used to compute the solutions, we showed that in most cases there is a good agreement among multiple solutions provided by different agencies. The intra-event variability in the ISC Bulletin was quantified by the maximum rotation angle and is well constrained up to $20^{\circ}$, which corresponds to a similarity coefficient of $\sim 80 \%$ (Cesca et al., 2013). As already mentioned above, both moment tensors and focal mechanism solutions are included in the ISC Bulletin. Since we needed to compare results obtained from these fundamentally different concepts, obtained by different techniques, we decided to focus on pure double couple and moment tensor best-fitting double couple mechanisms, which describe the geometry of the seismic source. For this reason the use of the rotation angle (Kagan, 1991) was selected. Different classification techniques and metrics could be applied (i.e. Helffrich, 1997; Frohlich and Davis, 1999), but for the purpose of the current 
article the rotation angle is considered to be an adequate metric of source mechanism variability. Similarly, by applying Zoback (1992) fault style classification, we observe a large intra-event variability for up to $8 \%$ of the earthquakes per year.

Source mechanisms are currently not reviewed by ISC analysts, and the user should pick, if required, the preferred one when multiple solutions are available for an event. The ISC values all agencies reporting source mechanism solutions and encourages new ones to submit theirs. In parallel, we recommend researchers make a more systematic use of the earthquake source mechanisms in the ISC Bulletin in future studies.

Author contributions. KL was the lead author of the paper and compiled most of the figures. DDG vetted the data for the magnitude and fault style plots, JH maintains the database and web services, and DAS obtained the funding for the work and established and maintained connections with many data providers. All the authors contributed to the manuscript and approved the final version.

Competing interests. The authors declare that they have no conflict of interest.

Acknowledgements. The authors wish to thank two anonymous reviewers for their comments and suggestions which helped to improve this paper. The work done at the ISC is possible thanks to the support of its members (http://www.isc.ac.uk/members/, last access: April 2019) and sponsors (http://www.isc.ac.uk/sponsors/, last access: April 2019). Work partially funded by NSF grants 1417970 and 1811737, and a USGS Award G18AP00035. Figures were drawn using the Generic Mapping Tools (Wessel et al., 2013) and the Matplotlib python library (Hunter, 2007).

Review statement. This paper was edited by Kirsten Elger and reviewed by two anonymous referees.

\section{References}

Adam, J.-C. and Romanowicz, B.: Global scale observations of scattered energy near the inner-core boundary: Seismic constraints on the base of the outer-core, Phys. Earth Planet. Inter., 245, 103-116, https://doi.org/10.1016/j.pepi.2015.06.005, 2015.

Aki, K. and Richards, P. G.: Quantitative Seismology: Theory and Methods, 2nd Edn., University Science Books, Sausalito, California, 2002.

Balfour, N. J., Cassidy, J. F., Dosso, S. E., and Mazzotti, S.: Mapping crustal stress and strain in southwest British Columbia, J. Geophys. Res., 116, B03314, https://doi.org/10.1029/2010jb008003, 2011.

Benz, H. M. and Herrmann, R. B.: Rapid Estimates of the Source Time Function and Mw using Empirical Green's Function DeconvolutionRapid Estimates of the Source Time Function and
Mw using EGF Deconvolution, Bull. Seismol. Soc. Am., 104, 1812, https://doi.org/10.1785/0120130325, 2014.

Bondár, I. and Storchak, D. A.: Improved location procedures at the International Seismological Centre, Geophys. J. Int., 186, 12201244, https://doi.org/10.1111/j.1365-246x.2011.05107.x, 2011.

Bormann, P., Liu, R., Xu, Z., Ren, K., Zhang, L., and Wendt, S.: First Application of the New IASPEI Teleseismic Magnitude Standards to Data of the China National Seismographic Network, Bull. Seismol. Soc. Am., 99, 1868-1891, https://doi.org/10.1785/0120080010, 2009.

Braunmiller, J., Kradolfer, U., Baer, M., and Giardini, D.: Regional moment tensor determination in the EuropeanMediterranean area - initial results, Tectonophysics, 356, 5-22, https://doi.org/10.1016/s0040-1951(02)00374-8, 2002.

Célérier, B.: Remarks on the relationship between the tectonic regime, the rake of the slip vectors, the dip of the nodal planes, and the plunges of the $P, B$, and $T$ axes of earthquake focal mechanisms, Tectonophysics, 482, 42-49, https://doi.org/10.1016/j.tecto.2009.03.006, 2010.

Cesca, S., Şen, A. T., and Dahm, T.: Seismicity monitoring by cluster analysis of moment tensors, Geophys. J. Int., 196, 1813-1826, https://doi.org/10.1093/gji/ggt492, 2013.

Chen, P. F., Nettles, M., Okal, E. A., and Ekström, G.: Centroid moment tensor solutions for intermediate-depth earthquakes of the WWSSN-HGLP era (1962-1975), Phys. Earth Planet. Inter., 124, 1-7, https://doi.org/10.1016/s0031-9201(00)00220-x, 2001.

Di Giacomo, D. and Storchak, D. A.: A scheme to set preferred magnitudes in the ISC Bulletin, J. Seismol., 20, 555-567, https://doi.org/10.1007/s10950-015-9543-7, 2015.

Dziewonski, A. M., Chou, T.-A., and Woodhouse, J. H.: Determination of earthquake source parameters from waveform data for studies of global and regional seismicity, J. Geophys. Res.-Solid, 86, 2825-2852, https://doi.org/10.1029/jb086ib04p02825, 1981.

Ekström, G., Nettles, M., and Dziewoński, A.: The global CMT project 2004-2010: Centroid-moment tensors for 13, 017 earthquakes, Phys. Earth Planet. Inter., 200-201, 1-9, https://doi.org/10.1016/j.pepi.2012.04.002, 2012.

Euler, G. G. and Wysession, M. E.: Geographic variations in lowermost mantle structure from the ray parameters and decay constants of core-diffracted waves, J. Geophys. Res.-Solid, 122, 5369-5394, https://doi.org/10.1002/2017jb013930, 2017.

Frohlich, C.: Triangle diagrams: ternary graphs to display similarity and diversity of earthquake focal mechanisms, Phys. Earth Planet. Inter., 75, 193-198, https://doi.org/10.1016/00319201(92)90130-n, 1992.

Frohlich, C. and Davis, S. D.: How well constrained are well-constrained $T, B$, and $P$ axes in moment tensor catalogs?, J. Geophys. Res.-Solid, 104, 4901-4910, https://doi.org/10.1029/1998jb900071, 1999.

Fukuyama, E., Ishida, S., Dreger, D. S., and Kawai, H.: Automated seismic moment tensor determination by using on-line broadband seismic waveforms, J. Seismol. Soc. Jpn., 2, 149-156, 1998.

Hasegawa, A., Yoshida, K., Asano, Y., Okada, T., Iinuma, T., and Ito, Y.: Change in stress field after the 2011 great TohokuOki earthquake, Earth Planet. Sc. Lett., 355-356, 231-243, https://doi.org/10.1016/j.eps1.2012.08.042, 2012.

Hayes, G. P., Rivera, L., and Kanamori, H.: Source Inversion of the W-Phase: Real-time Implementation and Exten- 
sion to Low Magnitudes, Seismol. Res. Lett., 80, 817-822, https://doi.org/10.1785/gssrl.80.5.817, 2009.

Hayes, G. P., Wald, D. J., and Johnson, R. L.: Slab1.0: A three-dimensional model of global subduction zone geometries, J. Geophys. Res.-Solid, 117, B01302, https://doi.org/10.1029/2011jb008524, 2012.

Helffrich, G. R.: How good are routinely determined focal mechanisms? Empirical statistics based on a comparison of Harvard, USGS and ERI moment tensors, Geophys. J. Int., 131, 741-750, https://doi.org/10.1111/j.1365-246x.1997.tb06609.x, 1997.

Huang, W.-C., Okal, E. A., Ekström, G., and Salganik, M. P.: Centroid moment tensor solutions for deep earthquakes predating the digital era: the World-Wide Standardized Seismograph Network dataset (1962-1976), Phys. Earth Planet. Inter., 99, 121129, https://doi.org/10.1016/s0031-9201(96)03177-9, 1997.

Hunter, J. D.: Matplotlib: A 2D graphics environment, Comput. Sci. Eng. 9, 90-95, 2007.

International Seismological Centre: On-line Bulletin, Internatl. Seismol. Cent., Thatcham, UK, available at: http://www.isc.ac.uk (last access: April 2019), 2018.

ISS: International Seismological Summary, annual volumes, available at: http://storing.ingv.it/ISS/index.html (last access: June 2018), 1938-1963.

Kagan, Y. Y.: 3-D rotation of double-couple earthquake sources, Geophys. J. Int., 106, 709-716, https://doi.org/10.1111/j.1365246x.1991.tb06343.x, 1991.

Kennett, B. L. N., Engdahl, E. R., and Buland, R.: Constraints on seismic velocities in the Earth from traveltimes, Geophys. J. Int., 122, 108-124, https://doi.org/10.1111/j.1365246x.1995.tb03540.x, 1995.

Lay, T., Duputel, Z., Ye, L., and Kanamori, H.: The December 7, 2012 Japan Trench intraplate doublet (Mw 7.2, 7.1) and interactions between near-trench intraplate thrust and normal faulting, Phys. Earth Planet. Inter., 220, 73-78, https://doi.org/10.1016/j.pepi.2013.04.009, 2013.

Lay, T., Ye, L., Koper, K. D., and Kanamori, H.: Assessment of teleseismically-determined source parameters for the April 25, $2015 M_{\mathrm{W}} 7.9$ Gorkha, Nepal earthquake and the May 12, $2015 M_{\mathrm{W}} 7.2$ aftershock, Tectonophysics, 714-715, 4-20, https://doi.org/10.1016/j.tecto.2016.05.023, 2017.

Lentas, K.: Towards routine determination of focal mechanisms obtained from first motion P-wave arrivals, Geophys. J. Int., 212, 1665-1686, https://doi.org/10.1093/gji/ggx503, 2017.

Lentas, K., Ferreira, A., Clévédé, E., and Roch, J.: Source models of great earthquakes from ultra low-frequency normal mode data, Phys. Earth Planet. Inter., 233, 41-67, https://doi.org/10.1016/j.pepi.2014.05.011, 2014

Lentas, K., Di Giacomo, D., Harris, J., and Storchak, D. A.: The ISC Bulletin as a comprehensive source of earthquake source mechanisms, https://doi.org/10.31905/D808B830, 2016.

Lomax, A. and Michelini, A.: Mwpd: a duration-amplitude procedure for rapid determination of earthquake magnitude and tsunamigenic potential from $\mathrm{P}$ waveforms, Geophys. J. Int., 176, 200-214, https://doi.org/10.1111/j.1365246x.2008.03974.x, 2009.

Meng, L., Ampuero, J.-P., and Bürgmann, R.: The 2013 Okhotsk deep-focus earthquake: Rupture beyond the metastable olivine wedge and thermally controlled rise time near the edge of a slab, Geophys. Res. Lett., 41, 3779-3785, https://doi.org/10.1002/2014gl059968, 2014.

Nakamura, M. and Mochizuki, E.: Focal mechanism solutions and their reliability determined by P-wave first motions, Quart. J. Seismol., 67, 11-20, 1988.

Okal, E. A.: "Detached" deep earthquakes: are they really?, Phys. Earth Planet. Inter., 127, 109-143, https://doi.org/10.1016/s0031-9201(01)00224-2, 2001.

Okal, E. A. and Newman, A. V.: Tsunami earthquakes: the quest for a regional signal, Phys. Earth Planet. Int., 124, 45-70, https://doi.org/10.1016/s0031-9201(01)00187-x, 2001.

Ozacar, A. A., Beck, S. L., and Christensen, D. H.: Source process of the 3 November 2002 Denali fault earthquake (central Alaska) from teleseismic observations, Geophys. Res. Lett., 30, 1638, https://doi.org/10.1029/2003gl017272, 2003.

Pondrelli, S., Salimbeni, S., Morelli, A., Ekström, G., Postpischl, L., Vannucci, G., and Boschi, E.: European-Mediterranean Regional Centroid Moment Tensor catalog: Solutions for 2005-2008, Phys. Earth Planet. Inter., 185, 74-81, https://doi.org/10.1016/j.pepi.2011.01.007, 2011.

Reasenberg, P. and Oppenheimer, D.: FPFIT, FPPLOT and FPPAGE; Fortran computer programs for calculating and displaying earthquake fault-plane solutions, US Geological Survey, Melno Park, California, https://doi.org/10.3133/ofr85739, 1985.

Rezapour, M. and Pearce, R. G.: Bias in surface-wave magnitude Ms due to inadequate distance corrections, Bull. Seismol. Soc. Am., 88, 43-61, 1998.

Shearer, P. M.: Evidence from a cluster of small earthquakes for a fault at $18 \mathrm{~km}$ depth beneath Oak Ridge, southern California, Bull. Seismol. Soc. Am., 88, 1327-1336, 1998.

Storchak, D. A., Harris, J., Brown, L., Kathrin, L., Shumba, B., Verney, R., Di Giacomo, D., and Korger, E. I. M.: Rebuild of the Bulletin of the International Seismological Centre (ISC), part 1: 1964-1979, Geosci. Lett., 4, 32, https://doi.org/10.1186/s40562017-0098-z, 2017.

Tsai, V. C., Nettles, M., Ekström, G., and Dziewonski, A. M.: Multiple CMT source analysis of the 2004 Sumatra earthquake, Geophys. Res. Lett., 32, L17304, https://doi.org/10.1029/2005g1023813, 2005.

Vallée, M., Charléty, J., Ferreira, A. M. G., Delouis, B., and Vergoz, J.: SCARDEC: a new technique for the rapid determination of seismic moment magnitude, focal mechanism and source time functions for large earthquakes using body-wave deconvolution, Geophys. J. Int., 184, 338-358, https://doi.org/10.1111/j.1365246x.2010.04836.x, 2010.

Wessel, P., Smith, W. H. F., Scharroo, R., Luis, J., and Wobbe, F.: Generic Mapping Tools: Improved Version Released, Eos Trans. Am. Geophys. Union, 94, 409-410, https://doi.org/10.1002/2013eo450001, 2013.

Weston, J., Engdahl, E., Harris, J., Di Giacomo, D., and Storchak, D.: ISC-EHB: reconstruction of a robust earthquake data set, Geophys. J. Int., 214, 474-484, https://doi.org/10.1093/gji/ggy155, 2018.

Willemann, R. J. and Storchak, D. A.: Data Collection at the International Seismological Centre, Seismol. Res. Lett., 72, 440-453, https://doi.org/10.1785/gssrl.72.4.440, 2001.

Ye, L., Lay, T., Kanamori, H., and Rivera, L.: Rupture characteristics of major and great $(\mathrm{Mw} \geq 7.0)$ megathrust earthquakes from 1990 to 2015: 1. Source parameter scal- 
ing relationships, J. Geophys. Res.-Solid, 121, 826-844, https://doi.org/10.1002/2015jb012426, 2016.

Zhan, Z. and Kanamori, H.: Recurring large deep earthquakes in Hindu Kush driven by a sinking slab, Geophys. Res. Lett., 43, 7433-7441, https://doi.org/10.1002/2016g1069603, 2016.
Zoback, M. L.: First- and second-order patterns of stress in the lithosphere: The World Stress Map Project, J. Geophys. Res., 97, 11703-11728, https://doi.org/10.1029/92jb00132, 1992. 